\title{
Sugarcane Mosaic Virus-Based Gene Silencing in Nicotiana benthamiana
}

\author{
Sajed Ali ${ }^{12^{*}}$, Idrees Ahmad Nasir ${ }^{2}$, Muhammad Rafiq ${ }^{3}$, Shahid Javed Butt ${ }^{1}$, Farooq Ihsan ${ }^{2}$, Abdul \\ Qayyum Rao ${ }^{2}$, Tayyab Husnain ${ }^{2}$ \\ ${ }^{1}$ Department of Biotechnology, School of Sciences, University of Management and Technology, Sialkot Campus, Sialkot, \\ Pakistan \\ ${ }^{2}$ Centre of Excellence in Molecular Biology, University of the Punjab, Lahore, Pakistan \\ ${ }^{3}$ Institute of Clinical Psychology, University of Management and Technology, Lahore, Pakistan
}

"Corresponding author: Sajed Ali, University of Management and Technology, Sialkot Campus, 21-A, Small Industrial Estate, Shahabpura Road, Sialkot, Pakistan. Tel: +92 32 16680406, E-mail: sajed.ali@skt.umt.edu.pk

Received: 29 March 2016; Revised: 14 February 2017; Accepted: 27 July 2017; Published online: 29 December 2017

\begin{abstract}
Background: Potyvirus-based virus-induced gene silencing (VIGS) is used for knocking down the expression of a target gene in numerous plant species. Sugarcane mosaic virus (SCMV) is a monopartite, positive single strand RNA virus.

Objectives: pBINTRA6 vector was modified by inserting a gene segment of SCMV in place of Tobacco rattle virus (TRV) genome part 1 (TRV1 or RNA1) and the two nonstructural proteins of TRV2(RNA2).

Materials and Methods: SCMV construct was inoculated into 3-4 weeks Nicotiana benthamiana plant leaves either by using a needleless syringe or applying pricking with a toothpick.

Results: The construct (SCMV-RNA2) successfully induced post-transcriptional gene silencing (PTGS) of the target genes GFP and ChlI through agroinoculation proving that SCMV is a substitute of the RNA1, which plays a pivotal role in the systemic gene silencing. 2-3-weeks of post inoculation, target genes' silencing was observed in the newly developed noninoculated leaves.

Conclusions: The newly developed construct expresses the knocked down of the endogenous as well as exogenous genes and only four weeks are required for the transient expression of the gene silencing based on SCMV-VIGS system.

Keywords: Nicotiana benthamiana, Post-transcriptional gene silencing, SCMV, Sugarcane mosaic virus, VIGS, Virus induced gene silencing.
\end{abstract}

\section{Background}

The emergence of sequencing data has helped the research in many model plants in general and in functional genomics in particular. Genome sequencing, next-generation sequencing, bioinformatics tools, shotgun sequencing, RNA-seq, expressed sequence tags, and microarrays have contributed largely in the research area of the biotechnology and molecular biology, respectively $(1,2)$. However, these tools lack in providing a comprehensive understanding of the functional consequence of the genes' sequences. The function of a gene could be understood through silencing gene expression experiments and stable mutant plant lines. Conversely, there is a limited cloning friendly insertional mutant resources, and what is available, is particularly available for Arabidopsis (3) as well as a small number of other plant species (Supplementary
Tables A and C). In addition, the identification of the mutant plant species can be achieved by targeting the induced local lesions in the genomes (TILLING) (4) in which the nucleotide sequences are well annotated and available (5). Gene overexpression and RNA interference (RNAi) studies are presently restricted to the plant species that are acquiescent to the genetic transformation, while, they are laborious and timeconsuming $(6,7)$. Micro-RNA-induced gene silencing $(8,9)$ and artificial micro-RNA-mediated gene silencing are used in plants for a targeted gene silencing, but these approaches involve a stable plant transformation, which is laborious, time consuming, and inappropriate with high-throughput studies (10-12). Similarly, a specific gene knockout in the plants can be used by clustered regularly interspaced short palindromic repeats (CRISPR) associated (Cas) nuclease (13), zinc-finger 
nucleases (ZFNs) (14), and transcription activator like effector nucleases (TALENs) (15). But, these methods require time consuming stable plant transformation and are mainly suitable as 'reverse genetics' tools.

Virus-induced silencing is a post transcriptional gene silencing method $(16,17)$ adopted by plants as a shield against viral attacks $(18,19)$. RNA dependent RNA polymerase produces double stranded RNA during the virus replication leading to PTGS (20-22). siRNA is produced by a process which involves Dicerlike enzyme-mediated cleavage of the dsRNA (23). RNA-induced silencing complex (RISC) chops the viral RNA in a homology-dependent manner (23) as a result of binding and activation of siRNA to RISC (Supplementary Fig. 1). This plant defense mechanism has been used for the development of a process for silencing of the endogenous plant genes (24). To silence a specific plant gene, a fragment of the target gene is cloned into a modified virus vector and delivered to the plant (25-27). The virus replication mechanism multiplies the target gene fragment introduced in the virus vector in the plant cell, and the transcripts spread throughout the plant systemically (28). The induced PTGS triggers the production of siRNA homologs, which will lead to the endogenous plant gene silencing (29).

Since the first report of VIGS in the late 1990s, it has been extensively used by many scientists for understanding and exploiting the role of plant genes in numerous biological processes $(24,30,31)$. The viral induced gene silencing has overcome many constraints. It favors to study gene functions when mutations are lethal to the embryonic stages and resulting into deformation of the plants $(26,32)$. It is also good for high-throughput genetic analysis (33-35), as it can be performed in a short time without any alteration in the plant genome $(36,37)$.

Various virus-induced gene silencing vectors have been developed which cause gene silencing of the many target genes in numerous plant species (38). Twentytwo VIGS vectors have been reported which are capable of multiple genes silencing in the multiple species (Supplementary Table B). Tobacco rattle virus (TRV) based VIGS vectors have been used in many plant species, particularly in Solanaceae family such as tomato (Solanum lycopersicum) and N. benthamiana $(37,39)$. Apple latent spherical virus (ALSV), Barley stripe mosaic virus (BSMV), Tobacco mosaic virus (TMV), Potato virus- $X$ (PVX), and Tomato golden mosaic virus (TGMV) have been reported as VIGS vectors capable of gene silencing in $N$. benthamiana $(39,40)$. PVX and TRV-based VIGS vectors express strong gene silencing in $N$. benthamiana. TRV has ability to infect meristem tissues (41), while others cannot.

Tobacco rattle virus (TRV) possesses bipartite genome: TRV1 (RNA1) and TRV2 (RNA2) (42). RNA 1 has a pivotal role in viral systemic movement (43). RNA1 encodes replicase proteins 134 and $194 \mathrm{kDa}$. RNA 2 has genes responsible for nonstructural and coat proteins (CP) and its genome shows diversity among its various isolates (42). The nonstructural proteins are associated with transmission to the nematodes (44), but these proteins have no role in plant infection. In this study, SCMV based VIGS vector was developed in order to trigger gene silencing of the both exogenous and endogenous genes in Nicotiana benthamiana.

\section{Objectives}

In this study, SCMV based VIGS vector was developed in order to trigger gene silencing of both exogenous and endogenous genes in Nicotiana benthamiana.

\section{Materials and Methods}

\subsection{Growth Conditions and Plant Material}

Plants of $N$. benthamiana were maintained in a restrained climatic condition in growth room at 20$25{ }^{\circ} \mathrm{C}$ with a $14 / 10 \mathrm{~h}$ light $\left(\sim 75 \mu\right.$ mol. $\left.\mathrm{m}^{-2} . \mathrm{s}^{-1}\right) /$ dark photoperiod. Seedlings were grown in a greenhouse until they attained the two leaf-stage and were ready for inoculation with the SCMV-VIGS construct. The inoculated plants were transferred to the growth room at $23-25^{\circ} \mathrm{C}$ until assessed.

\subsection{Construction of SCMV-VIGS Vectors}

For the development of SCMV based VIGS vector, RNA1 and the two nonstructural proteins of the RNA2 in pBINTRA6 (AF314165) (45) were substituted by Sugarcane mosaic virus CP gene segment. Moreover, multiple cloning sites for inserting fragments of the target gene to be silenced were also introduced (46) (Fig .1).The SCMV-RNA2 derived construct was then cloned into an Agrobacterium-mediated binary vector (pCAMBIA1300) for plant inoculation $(46,47)$ (Fig. 2). VIGS vector was constructed by using LBA4404 Agrobacterium strain. 313 bp cDNA was amplified from SCMV (Accession \# KC200152) using Pfu DNA polymerase applying the primer pair: SCMV-313-F (5'-TGCAGGAGCCCAAGGAGGGG-3') and SCMV313-R (5'-GGTGCTGCTGCACTCCCAACA-3'), respectively. The cDNA clone was inserted into the XmaI site of pBINTRA6 (AF314165)(45) and the resulting clones were confirmed by sequencing, and designated as the SCMV-RNA2 construct (Fig. 2). 


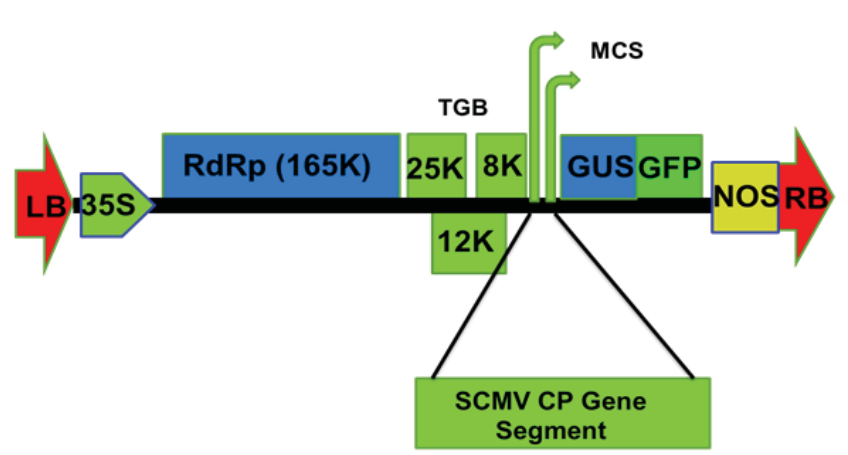

Figure 1. Details of the SCMV-RNA2 construct. The SCMV CP gene segment (313 nucleotides) was inserted into the XmaI site of the pBINTRA6 which enhances its systemic silencing of the both exogenous and endogenous genes of interest. RNA2 is the source of RdRp.

The same cloning strategy was adopted to clone a series of GFP and magnesium chelatase subunit I (ChlI) fragments. The selected sequences were amplified with primer pairs, GFP-F (5'-ATCGATGGTGATGTTAATGGGCAC-3') and GFP-R (5'-ATCGATGTCATGCCGTTTCAT ATG-3'). PCR products were purified, treated with T4 DNA polymerase at room temperature to generate sticky ends, followed by a heat treatment at $75{ }^{\circ} \mathrm{C}$ for $10 \mathrm{~min}$ to deactivate the polymerase. The $\mathrm{XmaI}$ linearized pBINTRA6 vector was subjected to the same treatment to create complementary sticky ends. The pBINTRA6 vector (20 ng) and PCR products ( $200 \mathrm{ng})$ were mixed, incubated for 2 minutes at $66{ }^{\circ} \mathrm{C}$ followed by a slow cooling to room temperature for annealing. Ten $\mu 1$ aliquots were used for cloning into Escherichia coli DH5- $\alpha$, and transformants were confirmed by endonuclease restriction digestions and colony PCR.

The $N$. benthamiana 200 bp ChII gene fragment was obtained by reverse transcriptase polymerase chain reaction (RT-PCR) (48) using the primer pair ChlI-F (5'-CTGAGGGTGTCAAGGCATTT-3') and ChlI-R (5'-TTCCGAATCGATCAAGAAGC-3'). The resulting fragment was integrated into pBINTRA 6 in the sense orientations to generate ChlI silencing construct (SCMV-ChlI).

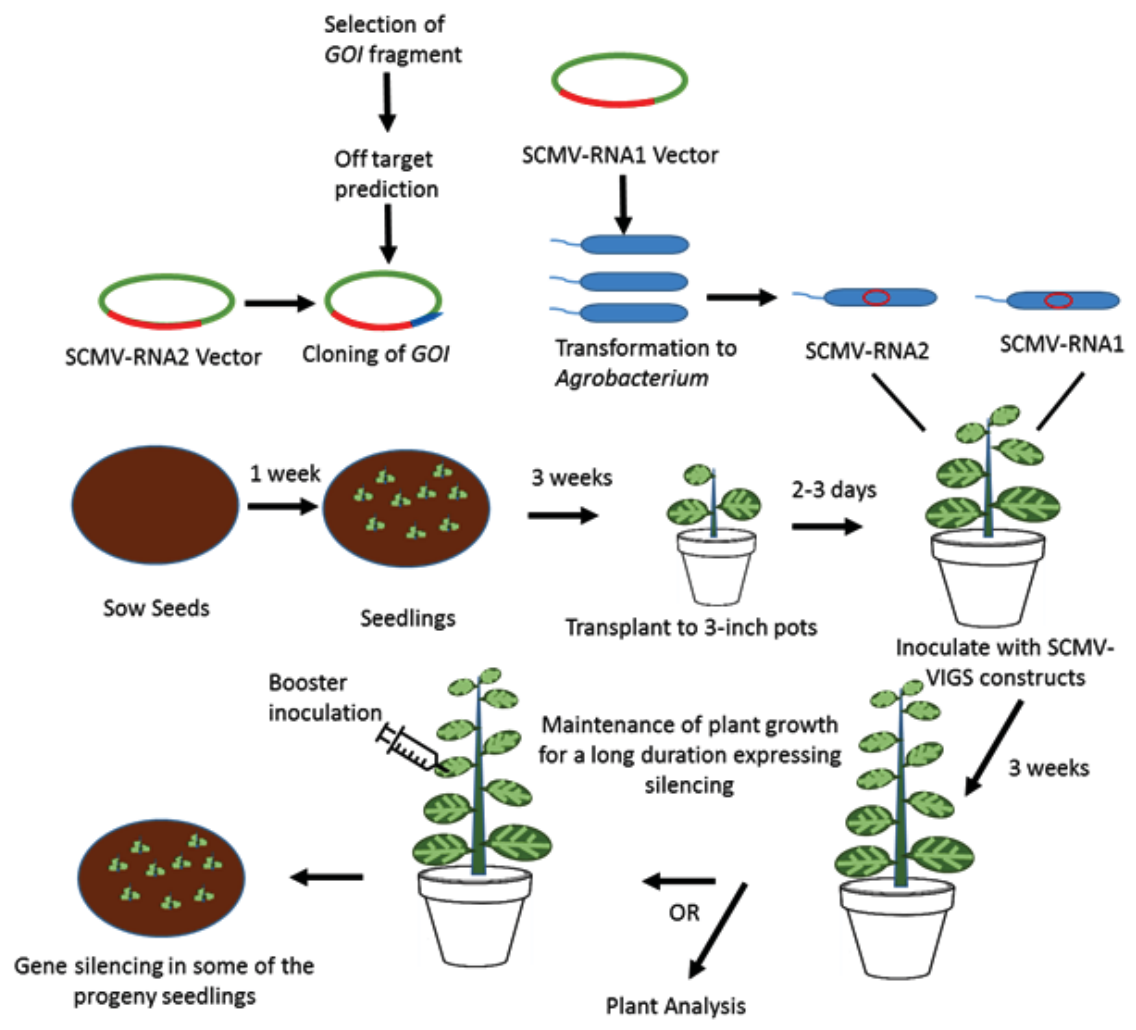

Figure 2. An overview of the SCMV based VIGS protocol in N. benthamiana. A GOI is cloned into the SCMV-RNA2 vector by either the gateway-based method or ligation-independent cloning depending on the vector. Transformation of the construct into Agrobacterium carried out and co-inoculation of the culture along with Agrobacterium carrying the construct into the 3-week-old plants accomplished. Silencing usually starts from the week 2 to the week 3 . The silenced plants can be used for analysis from 3 weeks after inoculation. Silencing can be maintained for longer periods by booster inoculations with SCMV-RNA2::GOI. 


\subsection{Agro-Infiltration of $N$. benthamiana.}

The SCMV based VIGS constructs were transformed into A. tumefaciens strain LBA4404 by electroporation method. Cultures were grown ready to use for agroinfiltration. Single colonies were incubated overnight at $28{ }^{\circ} \mathrm{C}$ while shaking in $5 \mathrm{~mL}$ of LB in the presence of antibiotic kanamycin $\left(100 \mu \mathrm{g} \cdot \mathrm{mL}^{-1}\right)$. One $\mathrm{mL}$ of the grown cultures was subcultured in $50 \mathrm{~mL}$ LB under the same growth conditions for $12 \mathrm{hrs}$. The bacterial cells were centrifuged for $10 \mathrm{~min}$ at 3000 $\times g$ and were mixed with infiltration buffer [10 $\mathrm{mM}$ $\mathrm{MgCl}_{2}, 10 \mathrm{mM}$ 2-(N-morpholino) ethanesulfonic acid (MES), pH 5.2, and $0.1 \mathrm{mM}$ acetosyringone]. The infiltration buffer was incubated for three hours at room temperature until $\sim 0.7 \mathrm{OD}_{600}$ was obtained.

SCMV-VIGS constructs were infiltrated into four to eight $N$. benthamiana leaves immediately above the cotyledons with a $1-\mathrm{mL}$ needleless syringe (Fig. 3 ). The infiltrated leaves were evaluated for silencing expression after maintenance in a growth chamber for 5 to 12 days post infiltration (dpi). Inoculation was also performed with either of the two methods: the agrodrench method and by pricking with a toothpick
(Fig. 3, supplementary Table 4).

\subsection{Semi-quantitative RT-PCR analysis}

TRIzol reagent was used to extract total RNA as described by the manufacturer (Invitrogen, Carlsbad, CA, USA). RNA was treated with DNase, and firststrand cDNA synthesis was carried out with M-MLV reverse transcriptase (Promega, Madison, WI, USA). The expression level of the target gene was monitored by semi-quantitative RT-PCR using gene-specific primers (Table 1) that anneal outside the region targeted for silencing.

\section{Results}

Plant phenotype may change due to silencing of a target gene; here GFP silencing changed to red under UV (Figs. 4B, D-E). Similarly, ChlI gene silencing resulted in a photobleaching in the plants (Figs. 4G-I). The ChlI gene is responsible for the biosynthesis of carotenoids (31). When this gene is silenced carotenoids level is reduced which protects photosystem. Hence, photooxidation is initiated resulting in photobleaching under ordinary light intensity $(31,46)$.

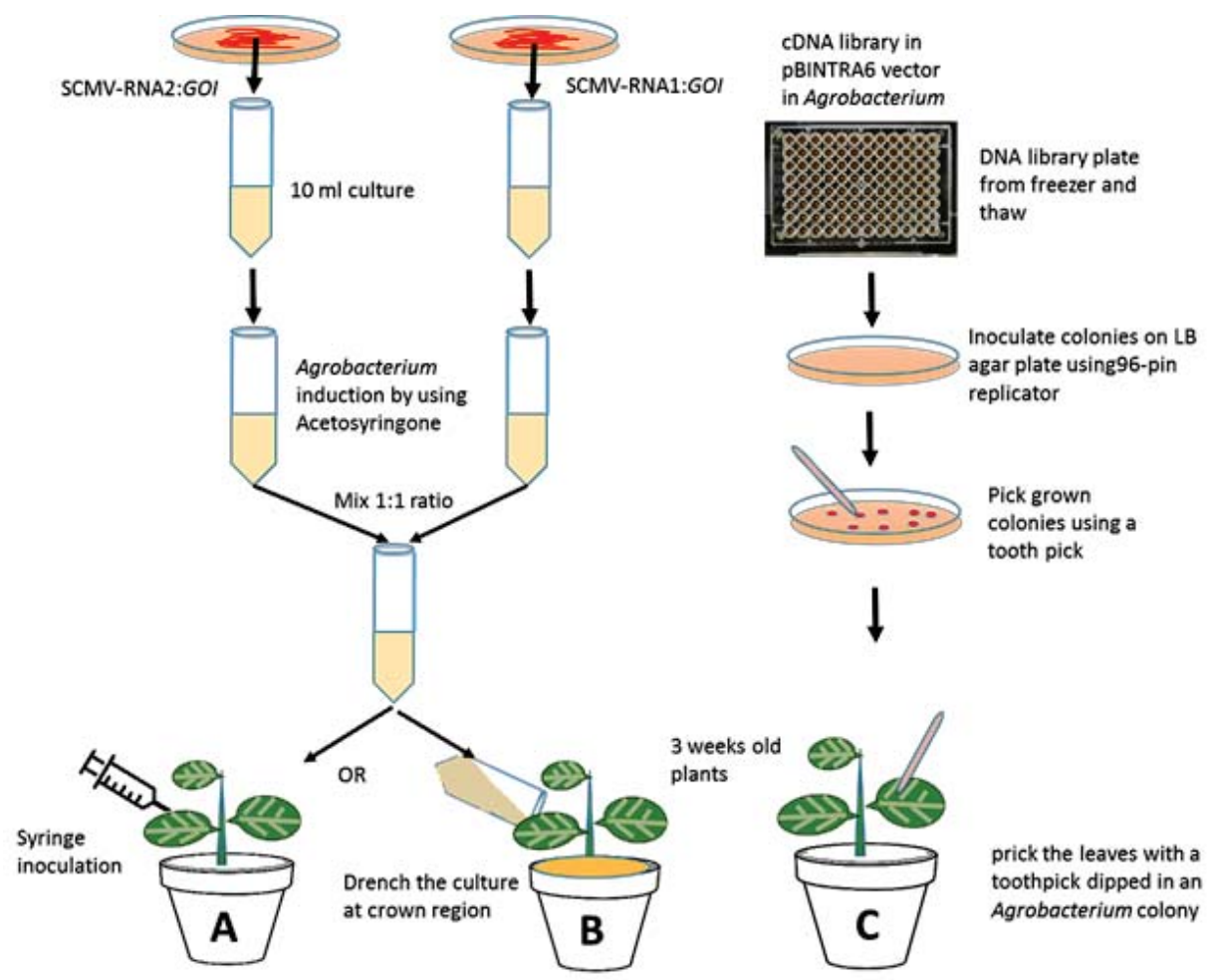

Figure 3. The different inoculation methods of the SCMV-RNA2 into N. benthamiana plants. (A) Agrobacterium cultures carrying SCMV-RNA2 containing target gene fragment (SCMV-RNA2::GOI) was inoculated into the leaves with a needleless syringe. (B) Agrodrench method that involves drenching of the crown region of the plant with the culture. (C) Another method is pricking the leaves with a toothpick dipped in an Agrobacterium colony carrying SCMV-RNA2::GOI. 
Ali S et al.

Table 1. The sequences of the primers used in this study.

\begin{tabular}{ccccc}
\hline Name & Primer Sequence (5'-3') & $\begin{array}{c}\text { Length } \\
(\mathbf{b p})\end{array}$ & $\mathbf{G C} \%$ & $\begin{array}{c}\text { Tm } \\
\left({ }^{\circ} \mathbf{C}\right)\end{array}$ \\
\hline SCMV-313-F & TGCAGGAGCCCAAGGAGGGG & 20 & 70 & 60 \\
SCMV-313-R & GGTGCTGCTGCACTCCCAACA & 21 & 62 & 58 \\
GFP-F & ATCGATGGTGATGTTAATGGGCAC & 24 & 46 & 55 \\
GFP-R & ATCGATGTCATGCCGTTTCATATG & 24 & 42 & 55 \\
Chl1-F & CTGAGGGTGTCAAGGCATTT & 20 & 50 & 52 \\
Chl1-R & TTCCGAATCGATCAAGAAGC & 20 & 45 & 52 \\
\hline
\end{tabular}

A

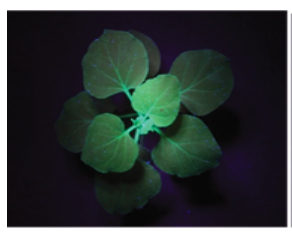

D

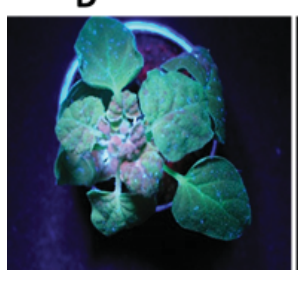

G
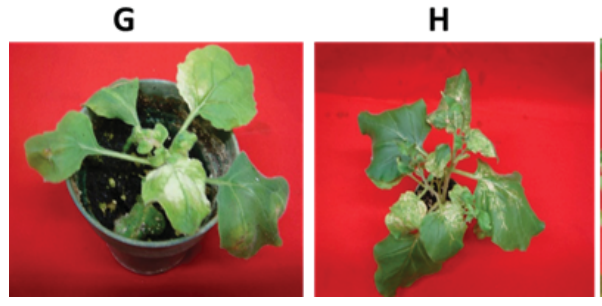

Figure 4. Silencing the GFP and ChlIgenes in $N$. benthamiana plants by SCMV-RNA2 based VIGS. (A) GFP transgenic plants of $N$. benthamiana under UV illumination. (B) Control (non-transgenic) N. benthamiana. (C) Control (non-transgenic) $N$. benthamiana under visible light. (D-F) The GFP gene (exogenous) silencing in 16-c transgenic $N$. benthamiana inoculated with the SCMV-RNA2 construct harboring GFP gene segment. The GFP sequence does not have any homology with the plant DNA therefore, it will not cause silencing. The plant was photographed at $\sim 2$ weeks after inoculation. (G-I) ChlI gene (endogenous) silencing (photobleaching) in $N$. benthamiana inoculated with the SCMV-RNA2 construct harboring ChlI gene segment, respectively.
RT-qPCR was used to evaluate the silencing levels of the target endogenous genes using gene-specific primers (Fig. 5). The degree of gene silencing depends on many factors i.e. intensity of the viral infection, time of VIGS construct inoculation and the expression of the target genes. $N$. benthamiana plants inoculated with SCMVRNA2:ChlI construct showed $>95 \%$ reduction in the transcript levels (Fig. 5), while, silencing ChlI gene by which phenotype photobleaching occurs, has noticed $\sim 15$ dpi (Figs. 4G-I). The silencing of the target gene is directly related to the degree of target gene function and silencing. Sometimes target genes are silenced, but they do not exhibit visual phenotype changes as compared with the control plants inoculated with the control vectors. The virus-induced gene silencing is assumed to be effective if $\sim 80 \%$ or greater downregulation of the endogenous target gene has occurred but it is governed by the nature and function of the genes (49). It has been observed that the inoculated plants can maintain the gene silencing for a couple of years and even in the next progeny, as well (50).

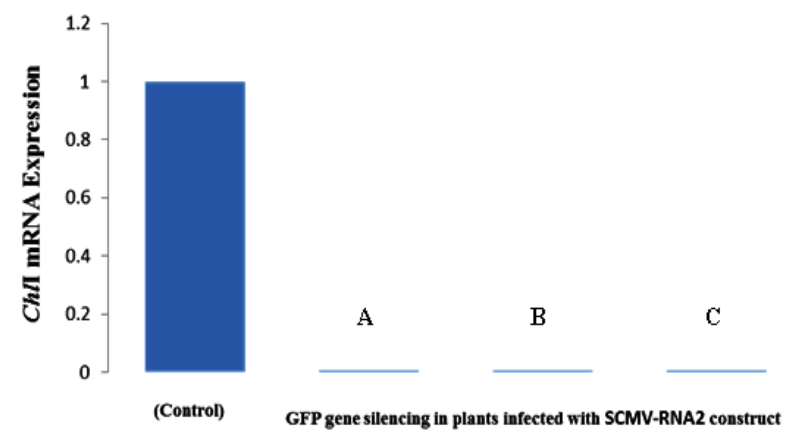

Figure 5. The endogenous ChlI transcript levels in the treated plants using different inoculation methods; A) syringe inoculation, B) agrodrenching, and C) picking compared with control plant, quantified using RT- qPCR. The inoculated plants show strong mRNA degradation. 
GFP gene (exogenous) silencing in transgenic $N$. benthamiana 16-c line, infected with SCMV-RNA2 construct harboring GFP gene segment, appeared as red under UV (Figs. 4D-F). Since GFP sequences do not possess homology with the plant DNA, and therefore any other gene(s) of the plant, it will not be silenced.

\section{Discussion}

The initial investigation on adapting SCMV-CPVIGS construct as a silencing vector was based on the wellestablished GFP silencing system (use of pBINTRA6 vector) in $N$. benthamiana line 16c (Ruiz et al., 1998). The construct cassette was restricted to GFP transgene expression under the control of the constitutive promoter $35 \mathrm{~S}$ derived from Cauliflower mosaic virus (CaMV) and NOS terminator (Fig. 1). The $N$. benthamiana 16c (GFP transgenic) plants normally appear to be green under UV illumination due to GFP fluorescence (Fig. $4 \mathrm{~A})$. In contrast, the non-transgenic $N$. benthamiana appears red (Fig. 4B) under UV illumination due to chlorophyll autofluorescence $(30,51)$. The results presented here indicate that a modified pBINTRA6 VIGS vector has efficiently worked as a silencer and as an expression vector in $N$. benthamiana. SCMV-RNA2 construct carrying the fragment of the GFP was capable of silencing GFP expression in N. benthamiana $16 \mathrm{c}$ when inoculated using potyvirus SCMV (Figs. 4 D-F) for the systemic silencing of the target gene(s). Further validation of the VIGS construct was done by cloning a fragment of endogenous gene ChlI into SCMV-RNA2 construct and inoculating it to the $N$. benthamiana. The inoculation yielded bleaching in the systemic leaves which is the characteristic of the loss of chlorophyll, providing a visible marker for gene silencing (Figs. 4G-I). The results confirmed that the vector is capable of initiating silencing of an endogenous gene in $N$. benthamiana (49).

The VIGS is a powerful technique for down-regulating gene expression in the plants (52-54). It is now widely used as a means of investigating gene function and has been adapted for high-throughput studies (33). Such an analysis would have been far more difficult and time consuming without the availability of VIGS.

GFP has been used extensively to study the systemic movement of the viruses in the plants e.g. CPreplacement vectors have been used to study the movement of Bean dwarf mosaic virus (BDMV) (55). These studies have shown that DNA viruses do not require the $\mathrm{CP}$ for systemic infection of the host plants $(56,57)$. However, for RNA viruses, the $\mathrm{CP}$ is essential for the infectivity as it is responsible for providing some essential movement functions, either as virions or as CP-RNA complexes (58-61). In pBINTRA6 (62) RNA1 and nonstructural protein genes of the RNA2 are involved in the systemic movement of the virus, but, silencing of the target genes was evident when they were replaced with the $S C M V-C P$ gene. Under UV illumination, silencing at the site of inoculation was evident. The silencing appeared as the red area around the site of infiltration. As well, a number of silencing patches were present in the developing leaves at the time of inoculation. It was evident from the results that silencing of the GFP along the veins has been initiated. The leaves above this (i.e. developing leaves after inoculation) initially showed silencing along the veins and later spread to the whole leaf surface systemically. All subsequently developing tissues were entirely silenced, thus appearing red under UV illumination. The silencing was persistent and remained until plants' senescence. Our results clearly have shown down regulation of GFP and ChlI in the $N$. benthamiana using our newly developed construct, named SCMV-RNA2.

\section{Acknowledgments}

We acknowledge the Higher Education Commission, Islamabad, Pakistan and professor Baulcombe's laboratory, Department of Plant Sciences, University of Cambridge, UK for providing us with the pBINTRA6 vector under a material transfer agreement.

\section{References}

1. Mochida K, Shinozaki K. Advances in omics and bioinformatics tools for systems analyses of plant functions. Plant Cell Physiol. 2011;52(12):2017-38. DOI: 10.1093/pcp/pcr153.

2. Hamilton JP, Robin Buell C. Advances in plant genome sequencing. Plant J. 2012;70(1):177-90. DOI: 10.1111/j.1365313X.2012.04894.X.

3. Alonso JM, Stepanova AN, Leisse TJ, Kim CJ, Chen H, Shinn P, et al. Genome-wide insertional mutagenesis of Arabidopsis thaliana. Science. 2003;301(5633):653-7. DOI: 10.1126/science.1086391.

4. Ritchie R, Wiley H, Szymanski D, Nielsen N. Targeting induced local lesions in genomes-TILLING. Legume crop genomics AOCS Book Press, Champaign, IL. 2004:194-203. DOI: 10.1201/9781439822265.ch12.

5. Fukai E, Małolepszy A, Sandal N, Hayashi M, Andersen SU. Forward and Reverse Genetics: The LORE1 Retrotransposon Insertion Mutants . In: The Lotus japonicus Genome: Springer; 2014. p. 221-7. DOI: 10.1007/978-3-662-44270-8 20.

6. Solinger JA, Poteryaev D, Spang A. Application of RNAi technology and fluorescent protein markers to study membrane traffic in C. elegans. In: Exocytosis and Endocytosis: Springer; 2014. p. 329-47. DOI: 10.1007/978-1-4939-0944-5_23.

7. Montes C, Castro Á, Barba P, Rubio J, Sánchez E, Carvajal D, et al. Differential RNAi responses of Nicotiana benthamiana individuals transformed with a hairpin-inducing construct during Plum pox virus challenge. Virus Genes. 2014;49(2):325-38.DOI: 10.1007/s11262-014-1093-5. 
8. Carbonell A, Takeda A, Fahlgren N, Johnson SC, Cuperus JT, Carrington JC. New Generation of Artificial MicroRNA and Synthetic Trans-Acting Small Interfering RNA Vectors for Efficient Gene Silencing in Arabidopsis. Plant Physiol. 2014;165(1):15-29. DOI: DOI:10.1104/pp.113.234989.

9. Jover-Gil S, Paz-Ares J, Micol JL, Ponce MR. Multi-gene silencing in Arabidopsis: a collection of artificial microRNAs targeting groups of paralogs encoding transcription factors. Plant J. 2014;80(1):149-60. DOI: 10.1111/tpj.12609.

10. Sha A, Zhao J, Yin K, Tang Y, Wang Y, Wei X, et al. Virus-based microRNA silencing in plants. Plant Physiol. 2014;164(1):36-47. DOI: 10.1104/pp.113.231100.

11. Bai Y, Han N, Wu J, Yang Y, Wang J, Zhu M, et al. A transient gene expression system using barley protoplasts to evaluate microRNAs for post-transcriptional regulation of their target genes. Plant Cell, Tissue Organ Culture (PCTOC). 2014;119(1):211-9.DOI: 10.1007/s11240-014-0527-z.

12. Sternberg SH, Redding S, Jinek M, Greene EC, Doudna JA. DNA interrogation by the CRISPR RNA-guided endonuclease Cas9. Nature. 2014. DOI:10.1038/nature13011.

13. Schiml S, Fauser F, Puchta H. The CRISPR/Cas system can be used as nuclease for in planta gene targeting and as paired nickases for directed mutagenesis in Arabidopsis resulting in heritable progeny. Plant J. 2014;80(6):1139-50. DOI: 10.1111/tpj.12704.

14. Lloyd A, Plaisier CL, Carroll D, Drews GN. Targeted mutagenesis using zinc-finger nucleases in Arabidopsis. Proceedings of the National Academy of Sciences of the United States of America. 2005;102(6):2232-7. DOI: 10.1073/pnas.0409339102.

15. Lor VS, Starker CG, Voytas DF, Weiss D, Olszewski NE. Targeted Mutagenesis of the Tomato PROCERA Gene Using Transcription Activator-Like Effector Nucleases. Plant Physiol. 2014;166(3):1288-91. DOI: 10.1104/pp.114.247593.

16. Robertson D. VIGS vectors for gene silencing: many targets, many tools. Annu Rev Plant Biol. 2004;55:495-519. DOI: 10.1146/annurev.arplant.55.031903.141803.

17. Burch-Smith TM, Anderson JC, Martin GB, Dinesh-Kumar SP. Applications and advantages of virus-induced gene silencing for gene function studies in plants. Plant J. 2004;39(5):734-46.DOI: 10.1111/j.1365-313X.2004.02158.x.

18. Petek M, Rotter A, Kogovšek P, Baebler Š, Mithöfer A, Gruden $\mathrm{K}$. Potato virus $\mathrm{Y}$ infection hinders potato defence response and renders plants more vulnerable to Colorado potato beetle attack. Mol Ecol. 2014;23(21):5378-91. DOI: 10.1111/mec.12932.

19. Bologna NG, Voinnet O. The Diversity, Biogenesis, and Activities of Endogenous Silencing Small RNAs in Arabidopsis. Ann Rev Plant Biol. 2014;65:473-503. DOI: 10.1146/annurevarplant-050213-035728.

20. Pumplin N, Voinnet O. RNA silencing suppression by plant pathogens: defence, counter-defence and counter-counterdefence. Nat Rev Microbiol. 2013;11(11):745-60.DOI:10.1038/ nrmicro3120.

21. Voloudakis AE, Holeva MC, Sarin LP, Bamford DH, Vargas M, Poranen MM, et al. Efficient Double-Stranded RNA Production Methods for Utilization in Plant Virus Control. Plant Virology Protocols: Springer; 2015. p. 255-74. DOI:10.1007/978-1-49391743-3_19.

22. Martínez de Alba AE, Elvira-Matelot E, Vaucheret H. Gene silencing in plants: a diversity of pathways. Biochimica et Biophysica Acta (BBA)-Gene Regulatory Mechanisms. 2013;1829(12):1300-8. DOI: 10.1016/j.bbagrm.2013.10.005.

23. Waterhouse PM, Wang M-B, Lough T. Gene silencing as an adaptive defence against viruses. Nature. 2001;411(6839):834-42. DOI:10.1038/35081168.

24. Ruiz MT, Voinnet O, Baulcombe DC. Initiation and maintenance of virus-induced gene silencing. Plant Cell Online. 1998;10(6):93746.DOI: $10.2307 / 3870680$.

25. Zhong X, Yuan X, Wu Z, Khan MA, Chen J, Li X, et al. Virusinduced gene silencing for comparative functional studies in Gladiolus hybridus. Plant cell Rep. 2014;33(2):301-12.DOI: 10.1007/s00299-013-1530-2.

26. Ramegowda V, Mysore KS, Senthil-Kumar M. Virus-induced gene silencing is a versatile tool for unraveling the functional relevance of multiple abiotic-stress-responsive genes in crop plants. Front Plant Sci. 2014;8;5:323. DOI: 10.3389/fpls.2014.00323.

27. Baulcombe DC. Fast forward genetics based on virus-induced gene silencing. Curr Opin Plant Biol. 1999;2(2):109-13. DOI:10.1016/S1369-5266(99)80022-3.

28. Schwach F, Vaistij FE, Jones L, Baulcombe DC. An RNAdependent RNA polymerase prevents meristem invasion by potato virus $\mathrm{X}$ and is required for the activity but not the production of a systemic silencing signal. Plant Physiol. 2005;138(4):1842-52. DOI: $10.1104 / p p .105 .063537$.

29. Brodersen P, Voinnet O. The diversity of RNA silencing pathways in plants. Trends Genet. 2006;22(5):268-80. DOI: 10.1016/j. tig.2006.03.003.

30. Burch-Smith TM, Anderson JC, Martin GB, Dinesh-Kumar SP. Applications and advantages of virus induced gene silencing for gene function studies in plants. Plant J. 2004;39(5):734-46. DOI: 10.1111/j.1365-313X.2004.02158.x.

31. Kumagai M, Donson J, Della-Cioppa G, Harvey D, Hanley K, Grill L. Cytoplasmic inhibition of carotenoid biosynthesis with virus-derived RNA. Proceedings of the National Academy of Sciences. 1995;92(5):1679-83. DOI: 10.1073/pnas.92.5.1679.

32. Lacomme C. Milestones in the development and applications of plant virus vector as gene silencing platforms. Plant Viral Vectors, Springer; 2014. p. 89-105. DOI: 10.1007/82_2011_186.

33. Yuan C, Li C, Yan L, Jackson AO, Liu Z, Han C, et al. A high throughput Barley stripe mosaic virus vector for virus induced gene silencing in monocots and dicots. PLoS One. 2011;6(10):e26468. DOI:10.1371/journal.pone.0026468.

34. Seaver SM, Gerdes S, Frelin O, Lerma-Ortiz C, Bradbury $\mathrm{LM}$, Zallot $\mathrm{R}$, et al. High-throughput comparison, functional annotation, and metabolic modeling of plant genomes using the PlantSEED resource. Proceedings of the National Academy of Sciences. 2014;111(26):9645-50.DOI: 10.1073/pnas.1401329111.

35. Mann DG, LaFayette PR, Abercrombie LL, King ZR, Mazarei M, Halter MC, et al. Gateway-compatible vectors for high-throughput gene functional analysis in switchgrass (Panicum virgatum L.) and other monocot species. Plant Biotech J. 2012;10(2):226-36. DOI: 10.1111/j.1467-7652.2011.00658.x.

36. Gupta B, Saha J, Sengupta A, Gupta K. Recent Advances on Virus Induced Gene Silencing (VIGS): Plant Functional Genomics. J Plant Biochem Physiol. 2013;1:e116. DOI: 10.4172/23299029.1000e116

37. Senthil-Kumar M, Mysore KS. New dimensions for VIGS in plant functional genomics. Trends Plant Sci. 2011;16(12):656-65. DOI: 10.1016/j.tplants.2011.08.006.

38. Becker A, Lange M. VIGS-genomics goes functional. Trends in plant science. 2010;15(1):1-4. DOI: $10.1016 / j$. tplants.2009.09.002.

39. Moreno-Valenzuela O, Villanueva-Alonzo H, Lopez-Ochoa L, Guerra-Peraza O, Robertson D, editors. Virus-induced gene 
silencing in Nicotiana benthamiana using a derivate vector of Euphorbia mosaic virus Yucatan Peninsula (EuMV-YP). Phytopathology; 2012; 102(7) 83. DOI: 10.1007/s10529-0131146-1.

40. Hayward A, Padmanabhan M, Dinesh-Kumar S. Virus-induced gene silencing in Nicotiana benthamiana and other plant species. Plant Reverse Genetics: Springer; 2011. p. 55-63. DOI: 10.1007/978-1-60761-682-5 5.

41. 41. Zhu F, Xi D-H, Deng X-G, Peng X-J, Tang H, Chen Y-J, et al. The Chilli Veinal Mottle Virus Regulates Expression of the Tobacco Mosaic Virus Resistance Gene N and Jasmonic Acid/ Ethylene Signaling Is Essential for Systemic Resistance Against Chilli Veinal Mottle Virus in Tobacco. Plant Mol Biol Rep. 2014;32(2):382-94.DOI: 10.1007/s11105-013-0654-4.

42. MacFarlane SA. Molecular biology of the tobraviruses. J Gener Virol. 1999;80(11):2799-807. DOI: 10.1099/0022-1317-80-112799.

43. Ziegler-Graff V, Guilford P, Baulcombe D. Tobacco rattle virus RNA-1 29K gene product potentiates viral movement and also affects symptom induction in tobacco. Virology. 1991;182(1):14555. DOI:10.1016/0042-6822(91)90658-X.

44. Visser PB, Bol JF. Nonstructural proteins of Tobacco rattle virus which have a role in nematode-transmission: expression pattern and interaction with viral coat protein. J Gener Virol. 1999;80(12):3273-80. DOI: 10.1099/0022-1317-80-12-3273.

45. Ratcliff F, Martin-Hernandez AM, Baulcombe DC. Technical advance: tobacco rattle virus as a vector for analysis of gene function by silencing. Plant J. 2001;25(2):237-45.DOI: 10.1046/j.0960-7412.2000.00942.x.

46. Ratcliff F, Martin-Hernandez AM, Baulcombe DC. Technical advance: tobacco rattle virus as a vector for analysis of gene function by silencing. Plant $J$. 2001;25(2):237-45.DOI: 10.1046/j.0960-7412.2000.00942.x.

47. Liu Y, Schiff M, Marathe R, Dinesh-Kumar S. Tobacco Rar1, EDS1 and NPR1/NIM1 like genes are required for $N$-mediated resistance to tobacco mosaic virus. The Plant Journal. 2002;30(4):415-29. DOI: 10.1046/j.1365-313X.2002.01297.x.

48. Murakami Y. [Reverse transcriptase-polymerase chain reaction]. Tanpakushitsu Kakusan Koso Protein, Nucleic Acid, Enzyme. 1996;41(5):595-602. DOI:10.1385/0-89603-499-2:149.

49. Senthil-Kumar M, Mysore KS. Tobacco rattle virus-based virusinduced gene silencing in Nicotiana benthamiana. Nat Protoc. 2014;9(7):1549-62.DOI:10.1038/nprot.2014.092.

50. Senthil Kumar M, Mysore KS. Virus induced gene silencing can persist for more than 2 years and also be transmitted to progeny seedlings in Nicotiana benthamiana and tomato. Plant Biotech $J$. 2011;9(7):797-806.DOI: 10.1111/j.1467-7652.2011.00589.x.

51. Baulcombe D. RNA silencing in plants. Nature. 2004;431(7006):356-63.DOI:10.1038/nature02874.

52. Zhu X, Pattathil S, Mazumder K, Brehm A, Hahn MG, DineshKumar S, et al. Virus-induced gene silencing offers a functional genomics platform for studying plant cell wall formation. $\mathrm{Mol}$ Plant. 2010:ssq023. DOI:10.1093/mp/ssq023.

53. Quadrana L, Rodriguez MC, López M, Bermúdez L, NunesNesi A, Fernie AR, et al. Coupling virus-induced gene silencing to exogenous green fluorescence protein expression provides a highly efficient system for functional genomics in Arabidopsis and across all stages of tomato fruit development. Plant Physiol. 2011;156(3):1278-91. DOI: 10.1104/pp.111.177345.

54. 54. Souza AJd, Mendes BMJ, Mourão Filho FdAA. Gene silencing: concepts, applications, and perspectives in woody plants. Scientia Agricola. 2007;64(6):645-56. DOI:10.1590/ S0103-90162007000600014.

55. Sudarshana M, Wang H, Lucas W, Gilbertson R. Dynamics of bean dwarf mosaic geminivirus cell-to-cell and long-distance movement in Phaseolus vulgaris revealed, using the green fluorescent protein. Mol Plant-Microbe Interact. 1998;11(4):27791. DOI: 10.1094/MPMI.1998.11.4.277.

56. Stanley J, Townsend R. Infectious mutants of cassava latent virus generated in vivo from intact recombinant DNA clones containing single copies of the genome. Nucleic Acid Res. 1986;14(15):598198. DOI: $10.1093 /$ nar/14.15.5981.

57. Azzam O, Frazer J, De La Rosa D, Beaver J, Ahlquist P, Maxwell D. Whitefly transmission and efficient ssDNA accumulation of bean golden mosaic geminivirus require functional coat protein. Virology. 1994;204(1):289-96.DOI: 10.1006/viro.1994.1533.

58. Boulton MI, Steinkellner H, Donson J, Markham PG, King DI, Davies JW. Mutational analysis of the virion-sense genes of maize streak virus. J Gen Virol. 1989;70(9):2309-23.DOI:10.1099/00221317-70-9-2309.

59. Qu F, Morris TJ. Efficient infection of Nicotiana benthamiana by Tomato bushy stunt virus is facilitated by the coat protein and maintained by $\mathrm{p} 19$ through suppression of gene silencing. Mol Plant-Microbe Interact. 2002;15(3):193-202.DOI:http://dx.doi. org/10.1094/MPMI.2002.15.3.193.

60. Callaway A, Giesman-Cookmeyer D, Gillock E, Sit T, Lommel $\mathrm{S}$. The multifunctional capsid proteins of plant RNA viruses. Ann Rev Phytopathol. 2001;39(1):419-60.DOI:10.1146/annurev. phyto.39.1.419.

61. Beachy RN, Loesch-Fries S, Tumer NE. Coat protein-mediated resistance against virus infection. Ann Rev Phytopathol. 1990;28(1):451-72. DOI:10.1146/annurev.py.28.090190.002315.

62. Ratcliff F, Martin Hernandez AM, Baulcombe DC. Technical advance: tobacco rattle virus as a vector for analysis of gene function by silencing. Plant J. 2001;25(2):237-45. DOI:10.1046/ j.0960-7412.2000.00942.x. 